\title{
RECENT DEVELOPMENTS IN WELDED HOLLOW SECTION JOINT RECOMMENDATIONS
}

\author{
Jaap Wardenier ${ }^{1, *}$ and Yoo Sang Choo $^{2}$ \\ ${ }^{1}$ Emeritus Professor, Faculty of Civil Engineering and Geosciences, \\ Delft University of Technology, P.O. Box 5048, 2600 GA Delft, The Netherlands \\ *(Corresponding author: E-mail: j.wardenier@citg.tudelft.nl) \\ ${ }^{2}$ Director, Centre for Offshore Research \& Engineering, Faculty of Engineering, \\ National University of Singapore, Kent Ridge, 117576 Singapore \\ cvecys@nus.edu.sg
}

\begin{abstract}
This paper considers recent research results on hollow section joints and the effect on the current design rules and is an extended version of the ICASS keynote lecture [1]. Main attention is paid to Rectangular Hollow Section (RHS) overlap joints, Circular Hollow Section (CHS) joints with thick-walled chords and the influence of the chord stress on the joint strength. Further, the effect of reinforcement plates on the strength of thinwalled joints is discussed. Also, some special aspects on elliptical hollow sections, stainless steel, high strength steel and delivery requirements for cold-formed hollow sections are considered. Finally, some developments regarding the fatigue design of hollow section joints are presented.
\end{abstract}

Keywords: Circular hollow section (CHS); Rectangular hollow section (RHS); Gap joints; Overlap joints; Static strength; Fatigue strength; High strength steel.

\section{NOMENCLATURE}

CHS

RHS

$\mathrm{A}_{\mathrm{i}}$

$\mathrm{A}_{\mathrm{s}}$

$\mathrm{F}_{\mathrm{u}, \mathrm{c}}$

$\mathrm{F}_{\mathrm{u}, \mathrm{u}}$

$\mathrm{M}_{0}$

$\mathrm{M}_{\mathrm{i}, 0}$

$\mathrm{M}_{\mathrm{i}, \mathrm{u}, \mathrm{c}}$

$\mathrm{M}_{\mathrm{i}, \mathrm{u}, \mathrm{u}}$

$\mathrm{M}_{\mathrm{o}, \mathrm{u}, \mathrm{c}}$

$\mathrm{M}_{\mathrm{o}, \mathrm{u}, \mathrm{u}}$

$\mathrm{M}_{\mathrm{pl}, 0}$

$\mathrm{N}_{\mathrm{i}}$

$\mathrm{N}_{\mathrm{j}}$

$\mathrm{N}_{0 \mathrm{p}}$

$\mathrm{N}_{0}$

$\mathrm{N}_{1,0}$

$\mathrm{N}_{\mathrm{i}, \mathrm{u}}$

$\mathrm{N}_{\mathrm{pl}, 0}$

$\mathrm{N}_{\mathrm{i} \text {, effec width }}$

$\mathrm{Ov}$

$\mathrm{R}_{\mathrm{N} 0-\mathrm{M} 0}$

$\mathrm{V}_{\mathrm{u}}$

$b_{i}$

$b_{j}$

$b_{0}$

$b_{\text {ei }}$

$b_{e j}$
Circular Hollow Section

Rectangular Hollow Section

cross section area of the overlapping brace member $i$

effective shear area of the joint

ultimate load capacity of the collar reinforced joint

ultimate load capacity of the of the unreinforced joint

in plane bending moment in the chord (general)

in plane bending moment in the chord in the plane $\mathrm{i}=1$ or 2

ultimate in plane bending moment capacity of the collar reinforced joint

ultimate in plane bending moment capacity of the unreinforced joint

ultimate out of plane bending moment capacity of the collar reinforced joint

ultimate out of plane bending moment capacity of the unreinforced joint

plastic moment capacity of the chord

axial force in the overlapping brace member $i$

axial force in the overlapped brace member $\mathrm{j}$

maximum prestressing force in the chord

maximum chord axial force

axial ultimate load capacity of the joint based on the load in member 1 for chord load nearly zero

axial ultimate load capacity of the joint based on the load in member $i$

plastic design capacity of the chord

ultimate load capacity of the overlapping brace based on the effective width criterion

Overlap in \%

interaction factor of bending moment and axial loading

ultimate shear capacity ratio

external width of the overlapping brace $\mathrm{i}$

external width of the overlapped brace $j$

external width of a chord

effective width of the overlapping brace $i$ with the chord connection

effective width of the overlapped brace $\mathrm{j}$ with the chord connection 


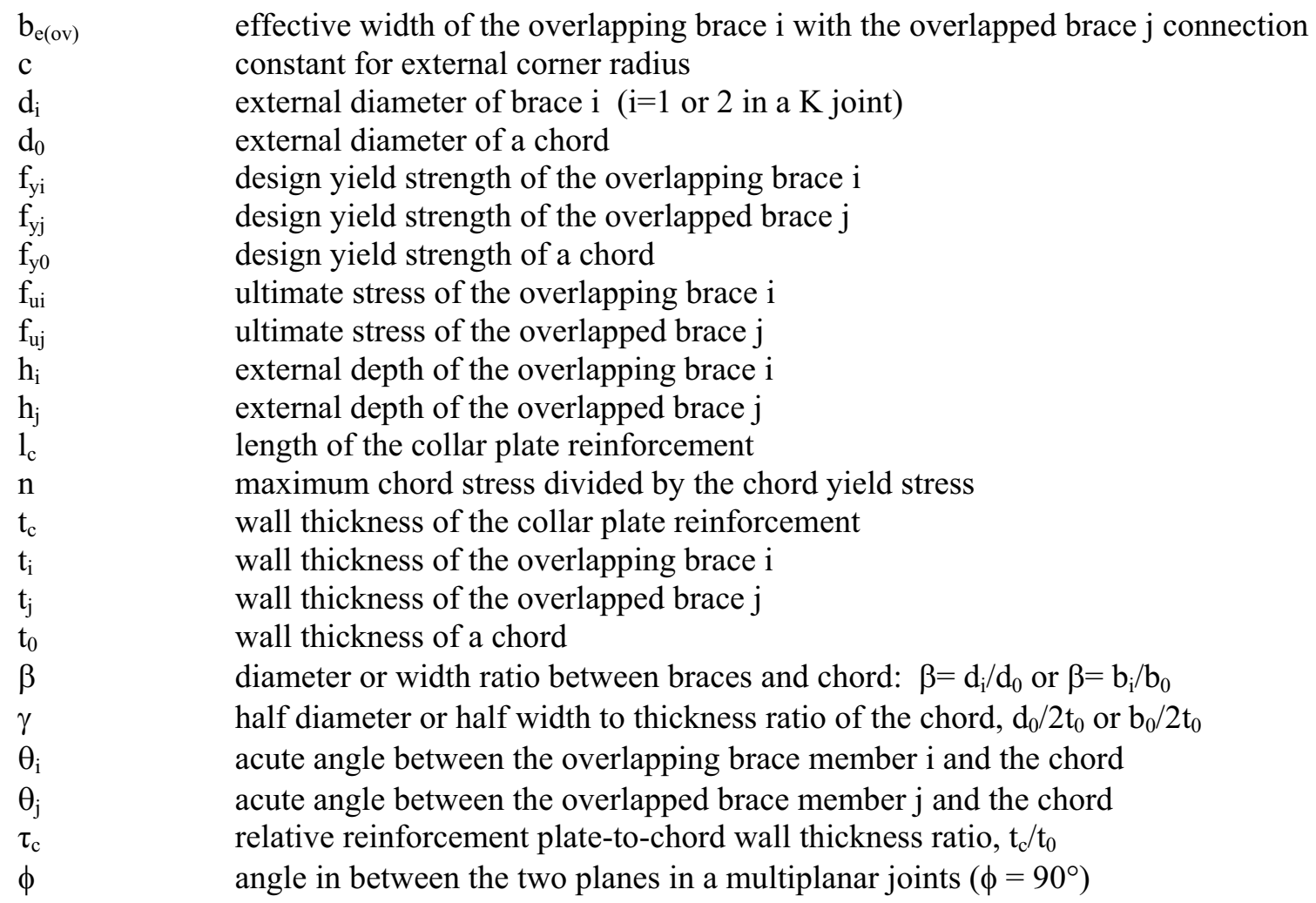

\section{INTRODUCTION}

The design rules in the second edition of the "Design Recommendations for Hollow Section Joints - Predominantly Statically Loaded" by the Sub-commission XV-E of the International Institute of Welding, (IIW-XV-E, 1989) [2] are the basis for many national and international design recommendations or standards, e.g. the Eurocode 3, (CEN, 2003) [3]. Based on these IIW-XV-E recommendations the Comité International pour le Développement et l'Etude de la Construction Tubulaire (CIDECT) has published several design guides for designers and fabricators, see for example [4].

Since the publication of the $2^{\text {nd }}$ edition of the IIW-XV-E recommendations, considerable research has been carried out in various areas, during the last years, including joints of very thin-walled and very thick-walled hollow sections. Further, research has been carried out to fill gaps in knowledge, e.g. multiplanar joints or for strength upgrading of joints in existing structures. Currently, the IIW$\mathrm{XV}$-E recommendations are revised and extended for the third edition [5]. Some of the research on which these revised recommendations and extensions are based, will be dealt with in this paper, as well as some other work in which the authors are involved.

For the fatigue design of hollow section joints the IIW-XV-E sub-committee has published in 1999 the "Recommended fatigue design procedure for welded hollow section joints", (IIW-XV-E, 1999) [6]. These recommendations are now the basis for drafting of an ISO standard. In these recommendations the fatigue design is based on the "hot spot stress" approach or also called the "geometrical stress" approach. Nowadays, such an approach becomes also usual for plated structures like ships and FPSO's. During the last few years, many investigations have been, or are still being carried out to compare and synchronize the various methods for the determination of the hot spot stress in relation to the fatigue classification and the thickness effect. 
This paper gives a brief review of some of the research recently carried out on hollow section joints, in particular those topics in which the authors are involved. Further, some other research is briefly discussed and references are given for more detailed information.

\section{STATIC DESIGN OF RECTANGULAR HOLLOW SECTION JOINTS}

\section{Uniplanar and multiplanar K-gap joints}

In the current CIDECT Design Guide for Rectangular Hollow Section Joints [7], it is recommended to assess multiplanar KK-gap joints with the uniplanar K-gap joint design formulae by applying a reduction factor of 0.9 . In addition a chord shear check should be performed for the gap location of gap joints.

Since the experimental evidence was limited, CIDECT initiated programme 5BJ in which all influencing parameters have been investigated [8]. In this research, it was found that in case of chord face failures, multiplanar KK-joints behaved nearly similar to uniplanar K-joints if the chords of the uniplanar joints were additionally loaded by a chord (pre)stressing force equal to $\mathrm{N}_{\mathrm{op}}=$ $-2 \mathrm{~N}_{\mathrm{i}}{ }^{*} \cos \theta_{\mathrm{i}}$ which represents the difference in the chord reaction force (see Figure 1).
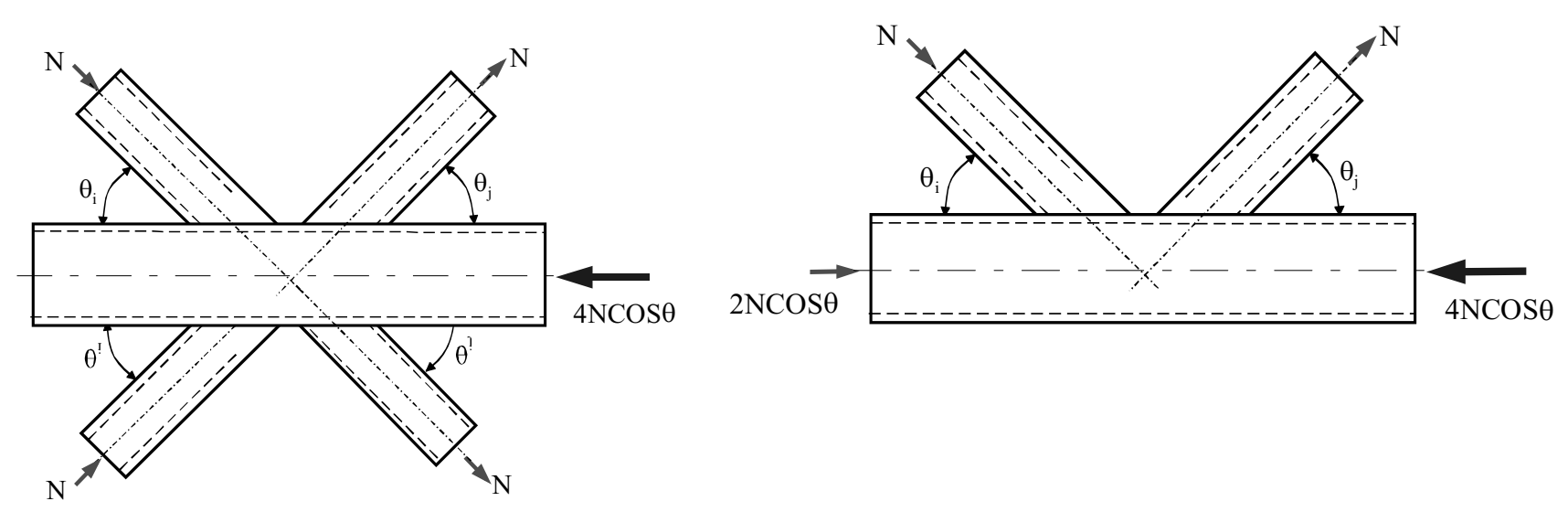

Figure 1. Uniplanar and multiplanar joints with equivalent behaviour

Consequently, it can be concluded that if for multiplanar KK-joints the larger chord load is taken into account in the chord stress function for chord face failure, the same formula can be used as for uniplanar K-joints and no further reduction factors have to be applied. However, due to the possible larger shear in the gap for particular loadings, the chord has always to be checked for the interaction of shear and axial load. The interaction is based on the well known Von Mises HuberHencky criterion. For example for a symmetrically loaded RHS multiplanar KK-joint with an included angle $\phi=90^{\circ}$ and no eccentricity, all sides of the RHS chord are loaded by axial load and shear and for each plane the following interaction Eq. (1) is valid:

$\left(\frac{\Sigma \mathrm{N}_{\mathrm{i}} \cdot \cos \theta_{\mathrm{i}}}{0.5 \mathrm{~A}_{0} \cdot \mathrm{f}_{\mathrm{y}}}\right)^{2}+\left(\frac{\Sigma \mathrm{N}_{\mathrm{i}} \cdot \sin \theta_{\mathrm{i}}}{0.5 \mathrm{~A}_{0} \cdot \mathrm{f}_{\mathrm{y}} / \sqrt{3}}\right)^{2} \leq 1.0$

For the multiplanar joint the chord axial load $\mathrm{N}_{0}$ is the sum of the horizontal components of the brace forces in both planes or two times the value in one plane. The resulting shear force $\mathrm{V}_{0}$ in the multiplanar joint is the vectorial resultant of the vertical components of the brace forces in both planes being $\sqrt{ } 2$ times the shear force in one plane. Thus the Eq. (1) can also be written as Eq. (1a): 
$\left(\frac{0.5 \mathrm{~N}_{0}}{0.5 \mathrm{~A}_{0} \cdot \mathrm{f}_{\mathrm{y}}}\right)^{2}+\left(\frac{\mathrm{V}_{0} \cdot \cos \phi_{\mathrm{j}} / 2}{0.5 \mathrm{~A}_{0} \cdot \mathrm{f}_{\mathrm{y}} / \sqrt{3}}\right)^{2} \leq 1.0$

or with $\mathrm{N}_{0, \mathrm{pl}}^{*}=\mathrm{A}_{0} \mathrm{f}_{\mathrm{y} 0}$ and $\mathrm{V}_{0, \mathrm{pl}}^{* *}=\mathrm{A}_{0} \mathrm{f}_{\mathrm{y} 0} / \sqrt{ } 3$ and $\varphi=90^{\circ}$ :

$\left(\frac{\mathrm{N}_{0}}{\mathrm{~N}_{0, \mathrm{pl}}^{*}}\right)^{2}+\left(\frac{1.4 \mathrm{~V}_{0}}{\mathrm{~V}_{0, \mathrm{pl}}^{* *}}\right)^{2} \leq 1.0$

In case of asymmetric loading or for $\varphi \neq 90^{\circ}$ it is easier to consider the interaction for each plane.

In the framework of a new CIDECT programme a numerical programme is being carried out to investigate the chord load functions for K-joints with gap. Based on the results, new chord load functions are being developed based on the maximum chord load [9]. The new proposed functions will have a format, which is similar for all types of circular and rectangular hollow section joints, as given below in Eq. (2):

$f(n)=\left[1-n^{c_{1}}\right]^{\left(c_{2}+c_{3} \beta+c_{4} \gamma\right)}$

Some of the results are shown in Figure 2 in comparison to the current chord stress function $[7,10]$.

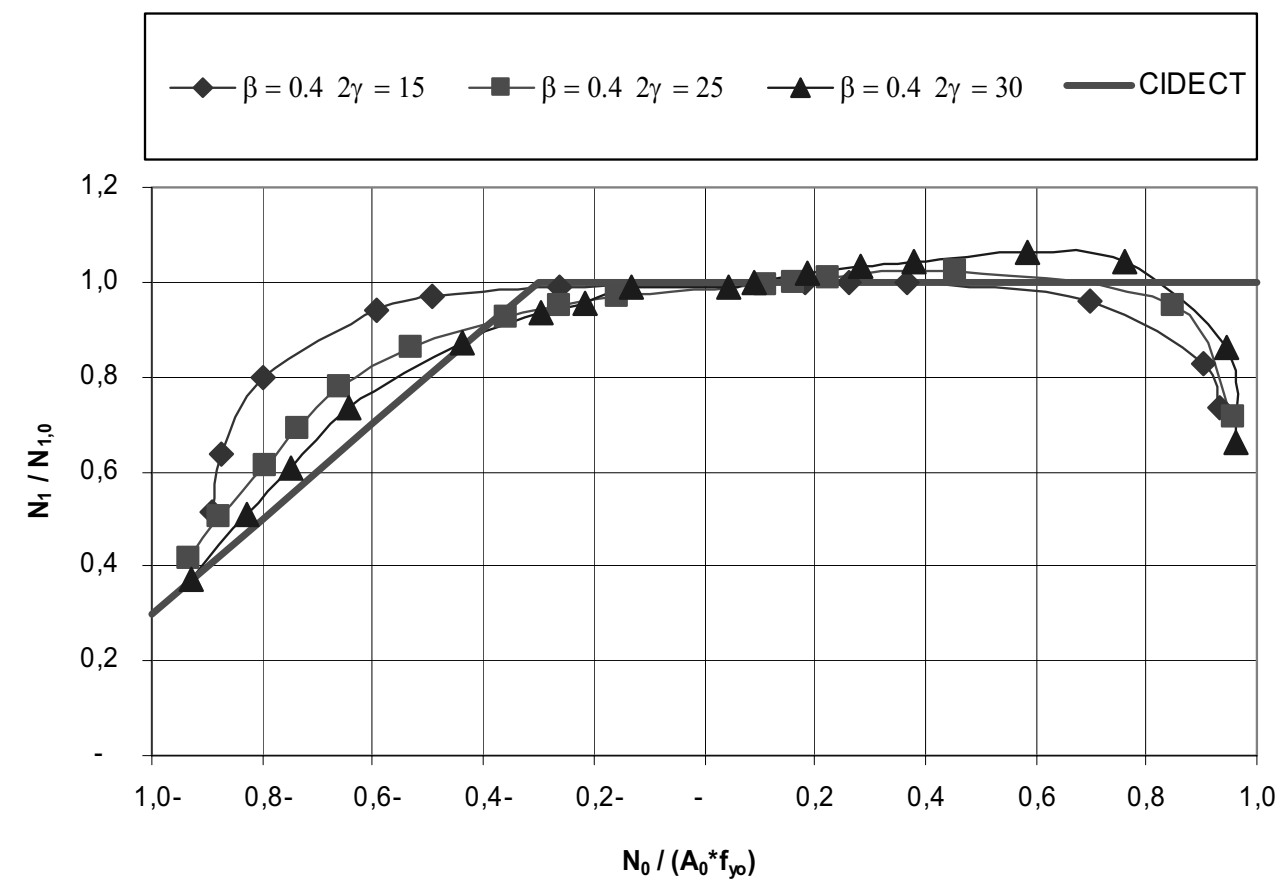

Figure 2. Chord stress reduction for RHS-K joints with gap $(\beta=0.4)$

In this study, as in other studies, it was shown that for $n>>0$, with chords loaded in tension a reduction factor also has to be applied, although the reduction is much smaller than for compression loading.

\section{Uniplanar and multiplanar K-overlap joints}

In the above-mentioned investigation it was also observed that, especially for multiplanar KKoverlap joints with medium to slender chord width to thickness ratios, chord face failure could occur which is not covered by the current codes and recommendations. Therefore, a detailed numerical study was carried out to study 50\% and 100\% uniplanar K- and multiplanar KK-overlap joints in more detail. 
Based on this study it was found that three failure modes have to be checked $[11,12]$, i.e.:

- overlapping brace failure (brace effective width criterion)

- brace shear failure at the connection with the chord

- local chord failure

The brace effective width criterion, e.g. shown in Figure 3 for a 100\% overlap joint, was already given in the current recommendations but the other two criteria are added, although the chord member has always to be checked for member failure. This investigation showed that at the joint location a linear interaction between axial load and bending moment is better than the member interaction formula. Besides these failure modes, it was found that the shear in the cross section of the braces just above the connection with the chord face has to be limited to avoid chord face failure. The first author indicated already in 1976 that brace shear failure at the connection with the chord face should be considered as a possible failure mode. However, brace shear failure was not observed in the experiments, which may be due to the small shear deformations. As a result this failure mode is not included in the current IIW and CIDECT recommendations and only a the brace effective width criterion was proposed to cover the strength of RHS overlap joints.

As indicated in Figure 4, the brace walls parallel to the chord axis are fully effective for shear and the brace cross wall at the heel is theoretically not effective or only effective for a part $b_{e}$. The toe part of the overlapped brace of an overlap joints with an overlap $\mathrm{Ov}<100 \%$ is generally not fully welded to the chord (hidden location) and therefore not effective; it is only fully effective in case of $100 \%$ overlap joints. The results for $100 \%$ overlap joints showed that in those cases where the joint capacity is not limited by other criteria, the ultimate shear capacity can be reached, i.e. $A_{s} \cdot \frac{f_{u}}{\sqrt{3}}$.

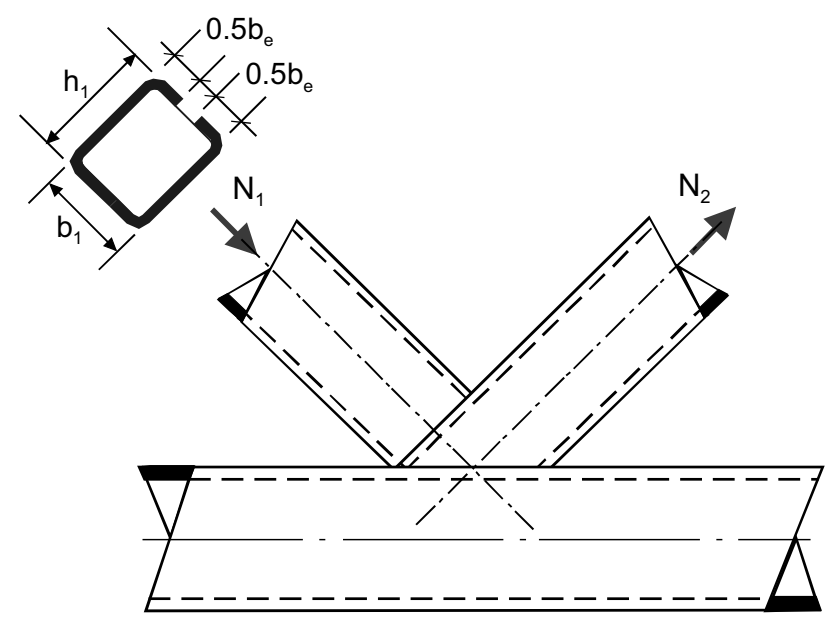

Figure 3. Brace effective width criterion for $100 \%$ overlap joints
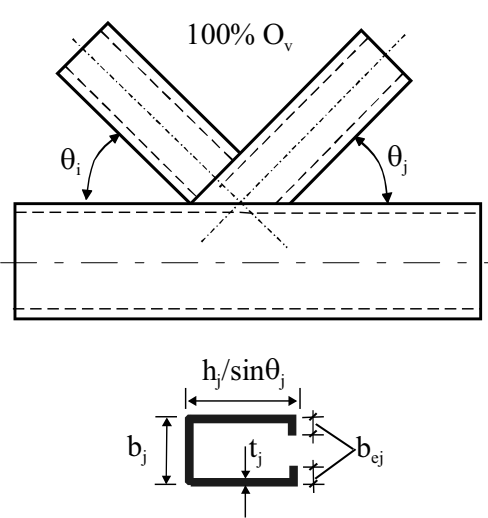
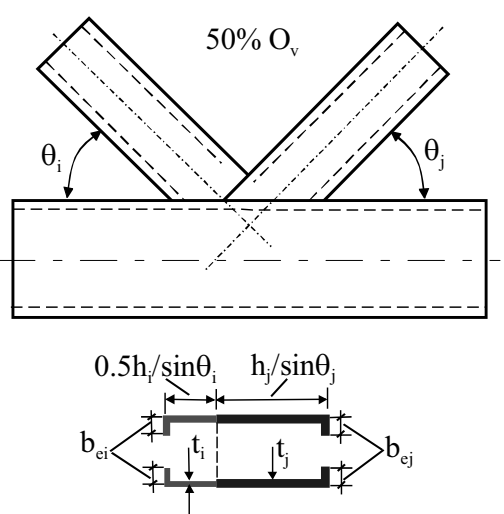

Figure 4. Joint configuration and definition of the shear area for $100 \%$ and $50 \%$ overlap joints 
Adopting this ultimate brace shear capacity limit to avoid chord face failures still gives an additional reserve in joint capacity of 1.1 to 1.15 .

Nowadays, higher strength steels are more frequently used, therefore, also the validity ranges for the width to thickness ratios have been reconsidered and are now related to the section class. In this case the section classes for the compression parts in hollow sections of Eurocode 3 are used.

Based on these studies the design recommendations are formulated as given in Table 1. The formulae are presented in a general format even allowing different steel grades for the overlapping and overlapped brace.

\section{Joints of thin-walled rectangular hollow sections}

Research on X, T and Y-joints of thin-walled hollow sections [13], indicated that the validity range of the width to thickness ratios in the design recommendations could, in particular cases, be more liberal. However, in actual structures always secondary effects like secondary moments exist and in case of thin-walled members these may cause premature failure because of lack of deformation and rotation capacity. Thus, using thin-walled sections outside the validity ranges of the current recommendations requires a more detailed elastic analysis. Further, it should be noted that in case of tests on joints of thin-walled sections all moments should be carefully measured because these may influence the axial load capacity due to the lower rotation/deformation capacity. Neglecting these moments may give test rig dependent test results.

\section{Joints of stainless steel rectangular hollow sections}

Rectangular hollow section joints of stainless steel, type $304 \mathrm{~L}$, have been investigated at the University of Sydney [14]. In these investigations, X and K-gap joints made of cold formed austenitic stainless steel hollow sections have been used. The ultimate strengths were compared with the IIW-CIDECT design equations and the joint deformation at service-ability (ultimate strength divided by 1.5 ) was compared with the $1 \%$ chord width criterion. It was concluded that if the $0.2 \%$ proof stress based on the cold formed finished product is used, the joint strength can be evaluated using the IIW-CIDECT design rules for hollow section joints made of carbon steel.

The joints loaded in tension fractured mainly through the weld in the heat affected zones. Thus, using electrodes of a stronger metal could even enhance the strength, allowing the $0.5 \%$ proof stress to be used in the formulae. In the analysis it was already shown that using the $0.5 \%$ proof stress, the service-ability limit was satisfied. However, the strength did not meet that according to the current IIW-CIDECT design equations for high chord loads. It is noted that the newly developed chord stress functions for rectangular hollow section joints (see before) are more conservative for high chord loads.

\section{Other investigated areas}

Other connections recently investigated more in detail and/or those still being investigated are e.g. plate-to-RHS connections at the University of Toronto by Kosteski \& Packer [15], corner connections, by Karcher \& Puthli [16], bird beak connections by Davies et al. [17] and bolted connections by Willibald et al. [18]. For detailed information, reference is given to the various proceedings of the International Symposia on Tubular Structures, for example, Jaurrietta et al. [19]. 
Table 1. Proposed design recommendations for RHS overlap joints

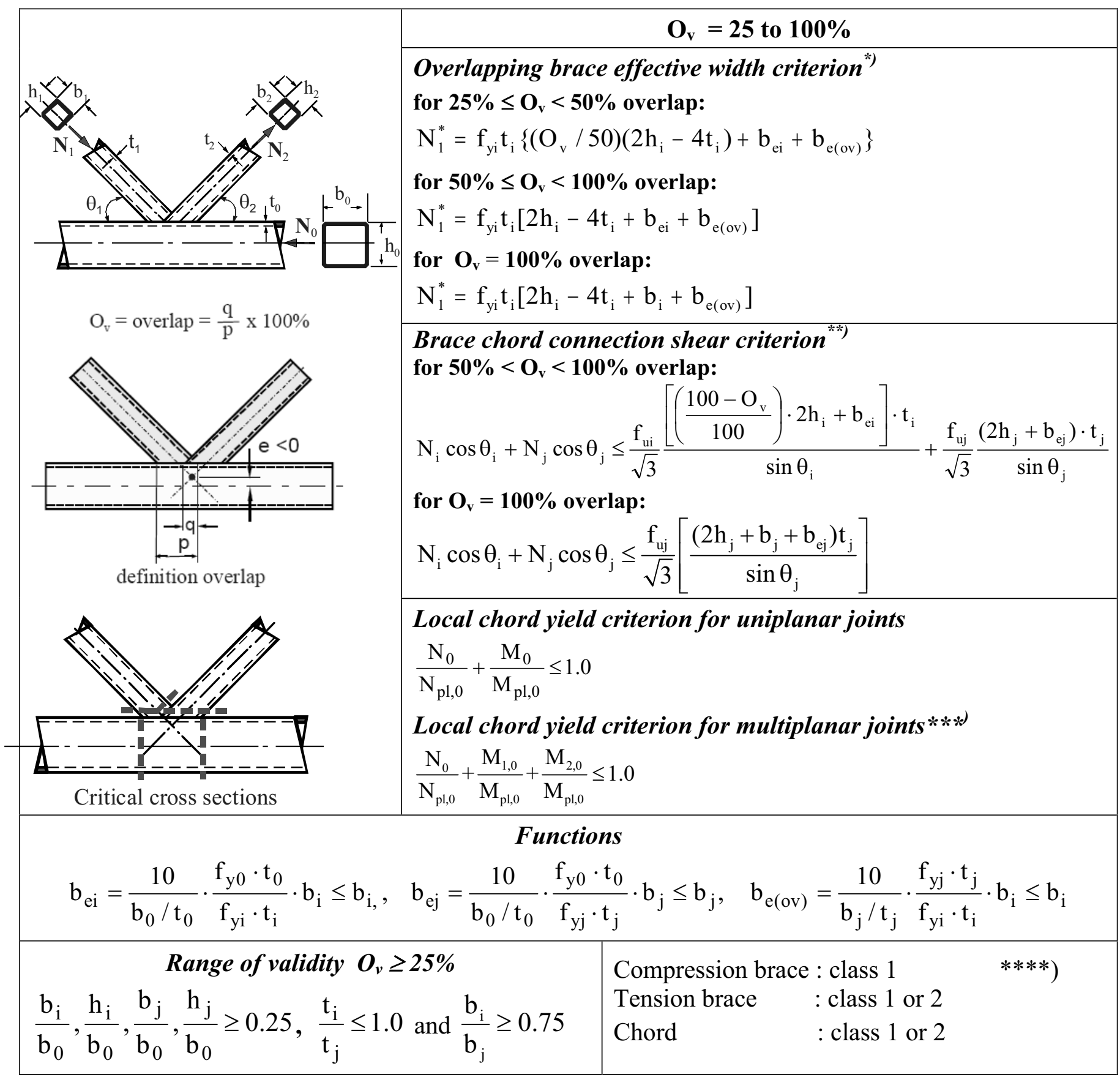

*) Efficiency capacity of the overlapped brace should not exceed that of the overlapping brace

**) This shear failure criterion is generally not critical for overlap joints with $\mathrm{O}_{\mathrm{v}} \leq 50 \%$. In this criterion with $\mathrm{O}_{\mathrm{v}}<100 \%$, it is assumed that the hidden location at the overlapped brace with the chord is not welded.

$* * *)$ The moments $\mathrm{M}_{1,0}$ and $\mathrm{M}_{2,0}$ are the in-plane moments in the two planes, respectively and $\mathrm{M}_{\mathrm{pl}, 0}$ and $\mathrm{M}_{\mathrm{pl}, 0}$ refers to the belonging in-plane plastic moment capacity of the chord.

\begin{tabular}{|l|c|c|c|c|}
\hline Limit (b-ct)/t & S 235 & S 275 & S 355 & S 460 \\
\hline Class 1 & 33 & 30 & 27 & 23 \\
\hline Class 2 & 38 & 35 & 31 & 27 \\
\hline
\end{tabular}

Note: $\mathrm{c}=3$ for hot formed hollow sections and $\mathrm{c}=5$ for cold formed hollow sections (rounded off figures). 


\section{STATIC DESIGN OF CIRCULAR HOLLOW SECTION JOINTS}

\section{Uniplanar and multiplanar joints}

The recommendations for circular hollow section joints in the offshore codes, e.g. the API [20] and the draft ISO, ISO TC67/SC7/WG3/P3 [21], differ from the IIW-XV-E and CIDECT recommendations. This is one of the reasons that the IIW-XV-E Sub-committee has decided to reanalyse the behaviour of circular hollow section joints as a basis to derive international consensus for the current revision of the IIW-XV-E recommendations. In the evaluation also other proposals, for example, Dexter \& Lee [22], Dier \& Lalani [23], Yamada et al. [24] and Choo \& Qian [25] are considered. Another aspect to be reviewed is the different behaviour of gap and overlap K-joints which in the current IIW recommendations are covered by only a single strength formula. It is the opinion of the authors of this paper that these joints should be dealt with separately. Overlap joints may be approached in a similar way as done for rectangular hollow sections.

Further, the influence of the chord stress on the joint strength of circular hollow sections is currently based on the so-called chord pre-load, i.e. the chord load minus the load, which reacts the brace load components. This is in contradiction with rectangular hollow section joints for which the chord load function is based on the maximum chord load. Therefore, in the framework of the CIDECT programme 5BK the existing formulae have been analysed and a numerical programme was carried out [26,27]. Based on this, new chord load functions were developed based on the maximum chord load. The new proposed functions have the general format of Eq. (2).

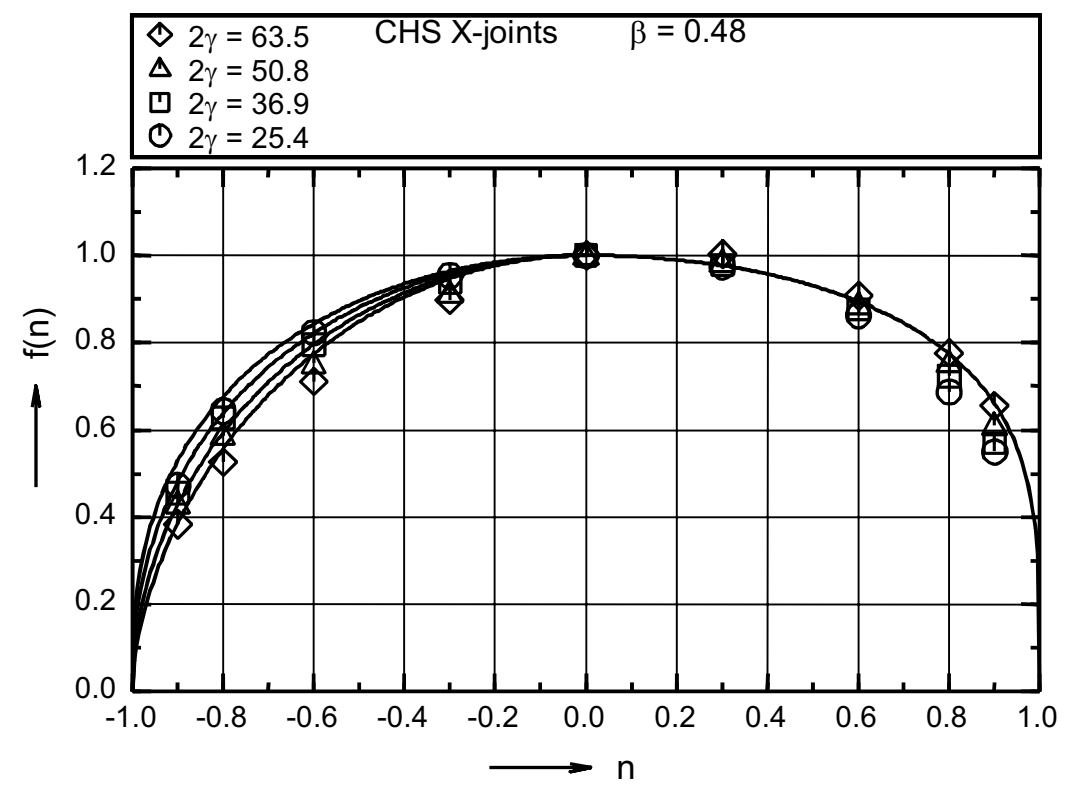

Figure 5. Chord stress reduction for CHS-X joints $(\beta=0.48)$

Also here, for chords loaded in tension $(\mathrm{n}>0)$, a reduction factor has to be applied. Figure 5 shows a typical example for a $\mathrm{X}$-joint with a diameter ratio $\beta=0.48$. The results have also been compared with recent work carried out by Pecknold et al. [28-29].

In the revised recommendations for $\mathrm{T}$ joints the chord stress to be used also includes the bending stress which always occurs due to brace loading. In the previous IIW-XV E recommendations and all other recommendations due to the experimental evidence this was indirectly also included in the joint capacity equations. With the current numerical methods it is easier to separate the influence of brace and chord loading [30] and to incorporate this in an easy way in the recommendations. 
Especially in the analyses of $\mathrm{K}$ gap joints the effect of the relatively large welds in small size experiments has to be excluded, that is why Yura [31] did not include in his analysis the test results of specimens with small chord members. In the past all recommendations have been based on experiments but the calculations with the current calibrated numerical models showed that the existing experimental data base has to be even more carefully screened. Furthermore, like for rectangular hollow section joints, a check may need to be carried out to ensure that the chord shear criterion in the gap is not critical. At present numerical calculations have been carried out for the whole parameter range and new strength equations have been developed. These new equations still need to be checked with the more refined experimental data base.

Currently various strength functions exist for overlap joints; some based on shear between the braces and punching shear, others relating the strength to that of gap joints. It is the authors opinion that the strength can be approached in a similar way as done for overlap joints of rectangular hollow sections with the effective parts related to the $\mathrm{d} / \mathrm{t}$ ratios of the relevant members, however, such a reanalysis has still to be done.

In the current CIDECT design guide 1 [32] based on the work of the Kumamoto team, it is recommended to assess multiplanar joints in each plane with the uniplanar joint strength formulae but applying a reduction factor of 0.9 . Additionally the chord has to be checked for shear in the gap. For rectangular hollow section joints it is shown above that the lower strength can be attributed to the larger chord force. By considering the maximum chord stress for the chord stress effect instead of the pre-stress due to additional chord loading, the reduction is in the same range but gives a consistent approach. This means that multiplanar K joints with gap of CHS (similar as RHS joints) can also be dealt with as uniplanar joints but taking account of the larger chord force and the additional shear check in the gap of the chord.

\section{Joints of thick-walled circular hollow sections}

In modern bridges and jack-up platform designs more and more use is made of very thick-walled hollow sections, sometimes in combination with cast steel nodes. As a consequence several investigations regarding the static behaviour of welded thick-walled joints have been carried out. The various investigations in this field are summarized by Choo \& Qian [25] and Choo [33].

The strength of circular hollow section joints with chord diameter to thickness ratios $2 \gamma \geq 15$ can generally be based on the simplified ring model and the punching shear model. However, for larger diameter ratios $\beta$ the strength deviation is more significant. This can readily be explained as follows: In the simplified ring model, as shown in Figure 6, the brace axial load is simplified to two line loads over an effective chord length $B_{e}$ and the joint strength is based on the plastic capacity of the chord with length $B_{e}$ (the ring) while neglecting the effect of the axial and shear forces on the plastic moment capacity.

This means that the joint strength is a function of $\mathrm{t}_{0}{ }^{2}$. However, for larger diameter ratios $\beta$ the load transfer is mainly by membrane action at the saddle location which means that the joint strength is a function of $\mathrm{t}_{0}$. For thick-walled chords this membrane load transfer becomes already more important for medium diameter ratios $\beta$. As a consequence the current design recommendations have to be modified to cover also joints with thick-walled chords and thus the different failure modes. 


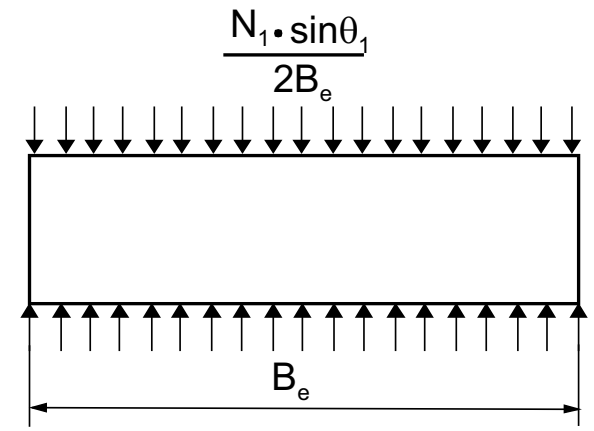

a: thin-walled chord

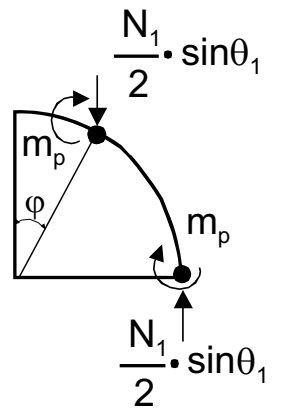

b: thick-walled chord

Figure 6. Ring model for thin- and thick-walled chords

In the investigations as summarised by Choo \& Qian [25], the joint strength is defined based on a plastic limit load definition which agrees with Lu's 3\% chord diameter limit for the joints with thinner chord sections. However, for joints with thick-walled chords the plastic limit load definition seems to give more consistent results. It was further observed that for $\mathrm{X}$ joints with a low inclined angle $\theta$ in combination with a larger brace to chord diameter ratio $\beta$, chord shear, as shown in Figure 7 can reduce the load capacity, which is not covered in the current design recommendations.

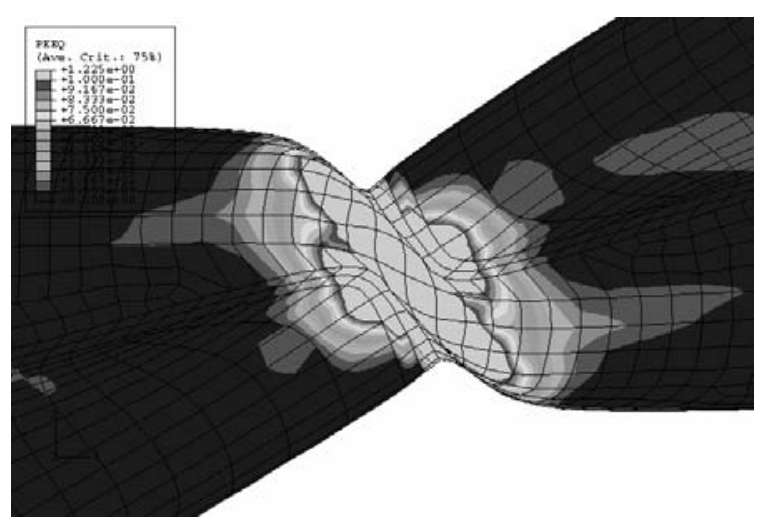

Figure 7. Interaction between chord plastification and chord shear in an $\mathrm{X}$ joint $\left(\theta=30^{\circ}, \beta=1.0\right.$ and $\left.2 \gamma=18\right)$

\section{Collar and doubler plate joints}

For the enhancement of the strength of joints with thin-walled chords, reinforcement by collar and doubler plates may be used, as highlighted by Choo et al. [34]. In case of collar plates, the brace is welded to the chord and the collar consisting of two or four parts is welded to the chord and the brace around the brace to chord connection, as shown in Figure 8. In case of doubler plates the doubler plate is welded to the chord and the brace is welded to the doubler plate.

These reinforced joints have been extensively investigated at the National University of Singapore under axial brace loading and under bending-in-plane moments, for example, as presented in [3437]. In all the investigations it was shown that for collar and doubler plates with a thickness equal or larger than that of the chord, the strength could be enhanced by $30 \%$ upwards, depending on the 
dimensions of the collar and doubler plates and geometrical parameters and the loading. As an example for joints with $2 \gamma=31.8$ and $\beta=0.43$, Figure 9 shows the ratio of the strength of the collar plate reinforced joint with respect to that of referenced un-reinforced joints, as a function of the relative plate-to-chord wall thickness ratio $\tau_{\mathrm{c}}\left(=\mathrm{t}_{\mathrm{d}} / \mathrm{t}_{0}\right)$ and the relative plate length to brace diameter ratio $1_{c} / d_{1}$. The strengthening effect is further depending on the loading, i.e. compression, tension, bending in-plane or bending out-of-plane.

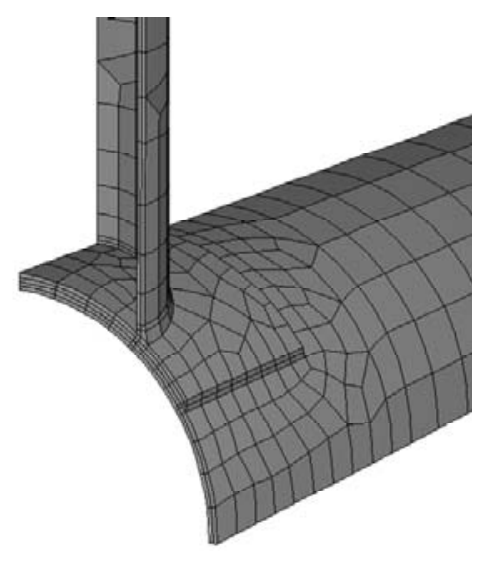

Doubler plate reinforced joint

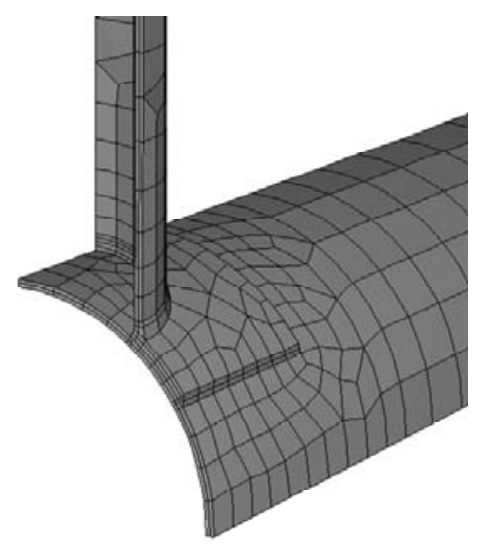

Collar plate reinforced joint

Figure 8. Collar and doubler plate stiffened joints
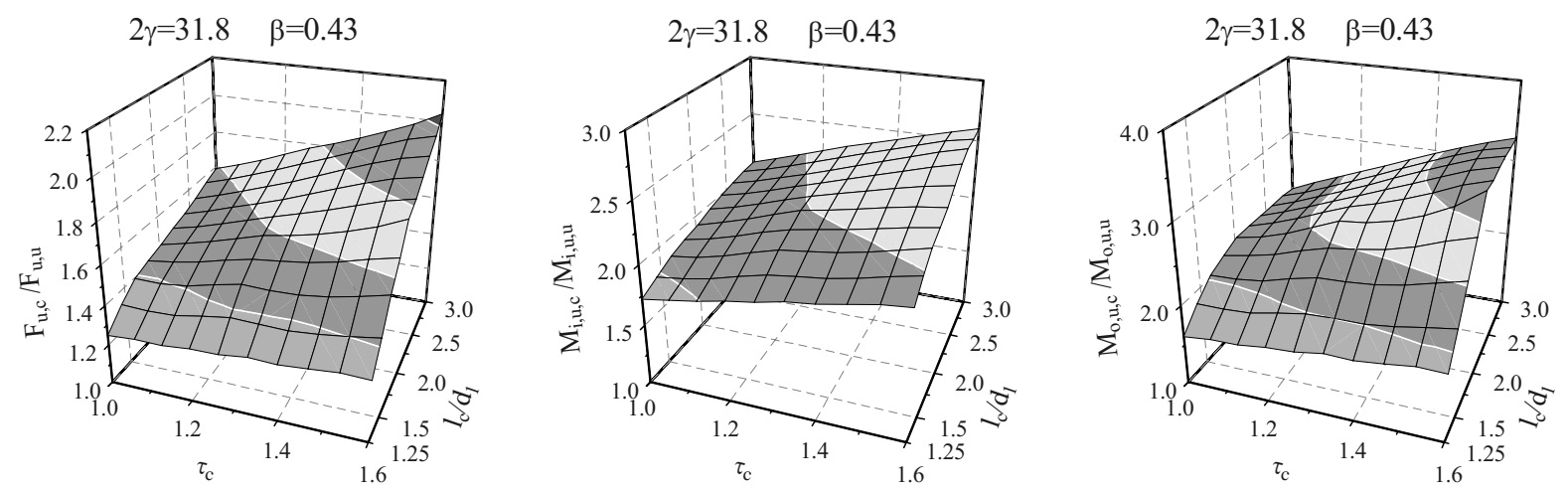

Figure 9. Normalised strengths of joints with collar plate reinforcement for (a) brace axial load, (b) in-plane bending, and (c) out-of-plane bending

\section{Ring-stiffened joints}

Although in the past several experimental and numerical investigations have been carried out, more evidence is becoming available for the design of these joints with the recent and improved numerical methods $[38,39]$.

\section{STATIC DESIGN OF JOINTS WITH HOLLOW SECTION BRACES AND AN I-SECTION CHORD}

The design equations for overlap joints with an I-section chord will be modified in a similar way as for rectangular hollow section joints, see Table 1 . This has not been investigated in tests but the behaviour is rather similar. 


\section{MISCELLANEOUS}

\section{Static design of elliptical hollow section joints}

Nowadays elliptical hollow sections are used in various architectural projects because of their special appearance. However, limited evidence is available on the joint behaviour.

Currently, research is underway at the University of Liege [40] and the National University of Singapore [41]. These initial investigations, show that the ring model can be used for explaining the numerically determined strengths. Further, research is being carried out at Toronto University to define the class limitations for the sections.

\section{Hollow section joints in high strength steel}

The revised IIW recommendations for hollow section joints will cover joints made of steels with design yield stresses up to $460 \mathrm{~N} / \mathrm{mm}^{2}$. Previously the validity was limited to steels with design yield stresses up to $355 \mathrm{~N} / \mathrm{mm}^{2}$. However, joints with higher yield stresses will have a lower ductility for redistribution (e.g. effective width and punching shear), a lower deformation capacity (e.g. thin-walled joints with a high $\beta$ ratio) or in other cases a larger deformation under service load (thin walled joints with a low $\beta$ ratio). Further, it was found by Kurobane [42], that the strength for circular hollow section K-joints is a function of the yield to ultimate stress ratio. The effect was found to be most pronounced for $\mathrm{K}$-joints for which the following relation was given:

$\left(\frac{f_{y}}{f_{u}}\right)^{-0.757}$

Figure 10 shows the relative effect related to the yield stress ratio for S235. It is shown that compared to K-joints of steel S 235 the non-dimensional strength of circular hollow section Kjoints of S 460 would drop by $17 \%$.

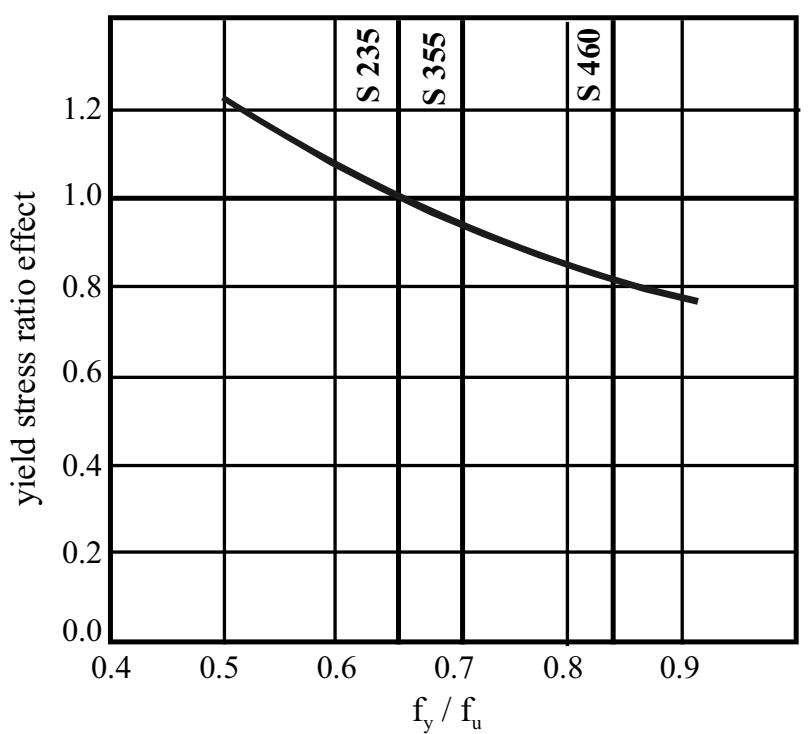

Figure 10. Influence yield to ultimate stress ratio for steel grades S 235, S 355 and S 460

Based on the ultimate strength only, without considering the ductility aspects and the larger deformation in Ref [43], it is proposed to limit the design yield stress to 0.8 times the ultimate stress, but even this does not fully compensate the lower non-dimensional strength. 
Additional numerical calculations at Delft University of Technology [44] using the 3\% of the chord width as ultimate deformation limit [45], showed that RHS K-joints made of S 460 had a 10 to $15 \%$ lower non-dimensional strength than comparable joints made from steel S 235, see Table 2.

Table 2. Non dimensional joint capacity related to the capacity for S 235

\begin{tabular}{|c|c|c|c|c|c|c|}
\hline \multirow{2}{*}{$2 \gamma$} & \multicolumn{7}{|c|}{$\beta$} \\
\cline { 2 - 7 } & \multicolumn{2}{|c|}{0.4} & \multicolumn{2}{|c|}{0.6} & \multicolumn{2}{c|}{0.8} \\
\cline { 2 - 7 } & $\mathrm{S} 355$ & $\mathrm{~S} 460$ & $\mathrm{~S} 355$ & $\mathbf{S ~ 4 6 0}$ & $\mathrm{S} 355$ & $\mathrm{~S} 460$ \\
\hline 15 & 0.95 & $\mathbf{0 . 9 0}$ & 0.92 & $\mathbf{0 . 8 4}$ & $0.96^{*}$ & $* *$ \\
\hline 25 & 0.95 & $\mathbf{0 . 8 9}$ & 0.95 & $\mathbf{0 . 9 0}$ & $0.96^{*}$ & $\mathbf{0 . 9 2}$ \\
\hline 30 & 0.95 & $\mathbf{0 . 9 0}$ & --- & --- & --- & -- \\
\hline 35 & --- & --- & 0.92 & $\mathbf{0 . 8 5}$ & $0.82^{*}$ & $\mathbf{0 . 7 7} *$ \\
\hline
\end{tabular}

The evaluation of the influence for the different steel grades on the static capacity of the joints is based on a factor R, which can be calculated by:

$\mathrm{R}=\frac{\mathrm{N}_{\text {ultimate, } \mathrm{S} \ldots}}{\mathrm{N}_{\text {ultimate }, \mathrm{S} 235}} \times \frac{\mathrm{f}_{\mathrm{y}}(\mathrm{S} 235)}{\mathrm{f}_{\mathrm{y}}(\mathrm{S} \ldots)}$

Considering the larger deformations in joints of S460 in case the failure modes corresponding to chord face failure (RHS) or chord plastification (CHS) are governing, and the lower ductility in case of punching shear failure and brace effective width failure, it is proposed to adopt a general reduction factor of 0.9 and to limit the yield stress $f_{y}$ to $0.8 f_{u}$ [44].

This avoids different corrections depending on the failure mode and this has been agreed by subcommission IIW-XV-E for joints in steels with design yield stresses exceeding $355 \mathrm{~N} / \mathrm{mm}^{2}$ up to $460 \mathrm{~N} / \mathrm{mm}^{2}$. This will result in a total joint capacity reduction of about $15 \%$.

Furthermore, the $b / t$ limitations given in the recommendations for the compression braces will be related to either class 1 or class 2 sections.

In Mang [46], it was shown that the strength of some tested K-joints made of S690 was only about $2 / 3$ of the predicted joint strength using the joint strength equations developed for S235, thus care has to taken to extrapolate the recommendations directly to joints of higher strength steel.

\section{Quality requirements for cold formed sections}

Since the available cold finished hollow sections on the market have different corner radii and different qualities, several investigations have been carried out during the last few years regarding checks for delivery requirements for cold-finished hollow sections [47]. Based on European research, e.g. recently at the University of Karlsruhe [48], it can be concluded that if welding is performed in or close to the corners, the corner radii have to meet the requirements given in Eurocode 3 [3], and in the IIW recommendations and recorded in Table 3. Furthermore, it is recommended to use fine-grained Al-killed steels. The modern steels are clean and have a low Carbon content. Si-killed steels may result in cracking after galvanizing. 
In Europe the cold finished sections are delivered according to EN 10219-Part 2 (1998) [49] and up to $12 \mathrm{~mm}$ the average corner radii agree with those of table 3 . However, a certain tolerance is allowed, which means that according to EN 10219 sections can be delivered with actual inner corner radii smaller than those in Table 3 . In the research programme sections were also tested with small corner radii which satisfy the tolerances of EN 10219 but with actual corner radii smaller than those in Table 3. These sections are only allowed to be welded in the corners if these satisfy EN 10219 with the following additional material requirements:

- The maximum nominal wall- thickness is not exceeding $12.5 \mathrm{~mm}$

- Aluminium killed steels with the quality grades $\mathrm{J} 2 \mathrm{H}, \mathrm{K} 2 \mathrm{H}, \mathrm{MH}, \mathrm{MLH}, \mathrm{NH}$ or NLH are used and

- the following maximum values are kept: $\mathrm{C} \leq 0.18 \%, \mathrm{P} \leq 0.020 \%$ and $\mathrm{S} \leq 0.012 \%$

In other cases welding is only permitted at a distance of $5 t$ from the corner or additional tests have to be performed to show that welding in the corners is permitted for that particular application. The requirements for steel S 460 are currently under discussion.

Table 3. Minimum inner corner radii for full aluminium $(\geq 0.02 \%)$ killed cold finished hollow sections to allow welding in the corners

\begin{tabular}{|c|c|c|c|}
\hline Steel grade & Wall thickness t $(\mathrm{mm})$ & $\begin{array}{c}\text { Minimum r/t } \\
(\mathrm{r}=\text { inner corner radius })\end{array}$ & Remarks \\
\hline & & & \\
\hline S235, S275, S355 & $\mathbf{2 4}$ & $\mathbf{3 . 0}$ & The steels are \\
(indicated by & $\mathbf{1 2}$ & $\mathbf{2 . 0}$ & indicated by \\
yield stresses in & $\mathbf{1 0}$ & $\mathbf{1 . 5}$ & yield stresses \\
$\mathrm{N} / \mathrm{mm}^{2}$ ) & $\mathbf{6}$ & $\mathbf{1 . 0}$ & in N/mm ${ }^{2}$ \\
\hline
\end{tabular}

No recommendation exists at present internationally for the determination of the required quality in relation to the service temperature, the welding condition, the loading, the static system, the thickness, the cold forming and the consequence of failure. According to the Dutch recommendations, NEN 6774 (2000) [50], the required quality for cold formed sections is generally one or two qualities higher than that required for hot-formed hollow sections. For example, if for a structural application in hot-formed hollow sections a Charpy value of $27 \mathrm{~J}$ at $20^{\circ}$ is required, then for equivalent cold finished hollow sections this Charpy value is required at a temperature of $0^{\circ}$ or $-20^{\circ}$. Further work on this topic is being carried out at the University of Lappeenranta [51], where RHS K joints are tested at various temperatures between $+20^{\circ} \mathrm{C}$ and $-60^{\circ} \mathrm{C}$. Based on this work it might be that proper selection criteria can be established.

\section{FATIGUE DESIGN OF HOLLOW SECTION JOINTS}

\section{General}

Based on the IIW-XV-E fatigue design recommendations for welded hollow section joints (IIWXV-E, 1999) [6], CIDECT has published a design guide [52]. Since the publication, additional research is going on for thin-walled hollow section joints at the Monash University of Melbourne, and at the University of Karlsruhe. Further, stress concentration factors for bird beak connections are determined at the Delft University of Technology [53]. The connections with cast-steel nodes are under investigation at the Universities of Lausanne and Karlsruhe. During the last years, progress is also made in the development of 3D fracture mechanics models, for example at Nanyang Technological University in Singapore, the National University of Singapore and Delft University of Technology [54-56]. Currently, the hot spot stress method is reviewed to derive at a common procedure for hollow section joints and plate connections [57,58]. 


\section{GENERAL}

At present still many investigations are going on and not all areas could be covered within the scope of this article. For example, many investigations just started in China, especially at the Tongji University, and it is expected that the coming years further improvements of the design rules may be expected.

In all areas the available information increases and many codes and recommendations become increasingly more voluminous and complicated with the probability of more errors. To the opinion of the authors, the information in codes should be limited to basic items and other relevant information should be given in background documents or design guides, for example, the CIDECT Design Guides and Packer \& Henderson [59]. Furthermore, the recommendations should be consistent and as simple as possible. In the education, emphasis should be given to understanding by using simple models $[60,61]$.

\section{ACKNOWLEDGEMENT}

The authors wish to thank their colleagues in the IIW-XV-E committee and the CIDECT technical commission for their friendship and collaboration. Further, appreciation is extended to Dr.D.K.Liu, Dr.G.J.van der Vegte and Dr.X.D.Qian for providing the figures and doing final layout checks.

\section{REFERENCES}

[1] Wardenier, J. and Choo, Y.S., "Some developments in tubular joint research", Proceedings of the $4^{\text {th }}$ International Conference on Advances in Steel Structures, Shanghai, China, Elsevier, 2005, Vol. 1, pp.31-40.

[2] IIW-XV-E, International Institute of Welding Subcommission XV-E, "Design recommendations for hollow section joints - Predominantly statically loaded", $2^{\text {nd }}$ Edition, IIW. Doc. XV-701-89, International Institute of Welding, Paris, France, 1989.

[3] CEN, Eurocode 3, "Design of steel structures, Part 1.8, Design of joints", Stage 49 Draft, Brussels, Belgium, November, 2003.

[4] Kurobane, Y., Packer, J.A., Wardenier, J. and Yeomans, N., "Design guide for structural hollow section column connections", TUV-Verlag GmbH, Cologne, Germany, 2004.

[5] Zhao, X-L., "Status of IIW static design recommendations for welded tubular joints", Proceedings of the $15^{\text {th }}$ International Offshore and Polar Engineering Conference, Seoul, Korea, 2005, Vol. IV, pp.264-271.

[6] IIW-XV-E, International Institute of Welding Subcommission XV-E, "Recommended fatigue design procedure for welded hollow section joints, Part 1: Recommendations and Part 2: Commentary", IIW. Docs. XV-1035-99/XIII-1804-99, International Institute of Welding, Paris, France, 1999.

[7] Packer, J.A., Wardenier, J., Kurobane, Y., Dutta, D. and Yeomans, N., "Design guide for rectangular hollow section (RHS) joints under predominantly static loading", TUV-Verlag $\mathrm{GmbH}$, Cologne, Germany, 1992.

[8] Liu, D.K. and Wardenier, J., "Multiplanar influence on the strength of RHS multiplanar gap KK-joints", Proceedings of the $9^{\text {th }}$ International Symposium on Tubular Structures, Düsseldorf, Germany, Tubular Structures IX, A.A.Balkema Publishers, Lisse, The Netherlands, 2001, pp.203-212. 
[9] Liu, D.K. and Wardenier, J., "New chord stress functions for RHS gap K-joints", To be presented at the $11^{\text {th }}$ International Symposium on Tubular Structures, Quebec City, Canada, 2006.

[10] Wardenier, J., "Hollow section joints", Delft University Press, Delft, The Netherlands, 1982.

[11] Chen, Y.Q., Liu, D.K. and Wardenier, J., "Design recommendations for RHS K-joints with $100 \%$ overlap", Proceedings of the $15^{\text {th }}$ International Offshore and Polar Engineering Conference, Seoul, Korea, 2005, Vol. IV, pp.300-307.

[12] Liu, D.K., Chen, Y.Q. and Wardenier, J., "Design recommendations for RHS K-joints with $50 \%$ overlap", Proceedings of the $15^{\text {th }}$ International Offshore and Polar Engineering Conference, Seoul, Korea, 2005, Vol. IV, pp.308-315.

[13] Veselcic, M., Herion, S. and Puthli, R.S., "Static behaviour of X, T and Y joints made of thin-walled RHS under brace axial load", Proceedings of the $9^{\text {th }}$ International Symposium on Tubular Structures, Düsseldorf, Germany, Tubular Structures IX, A.A.Balkema Publishers, Lisse, The Netherlands, 2001, pp.155-164.

[14] Rasmussen, J.R. and Young, B., "Tests on X- and K-joints in SHS stainless steel tubes", Journal of Structural Engineering, ASCE, 2001, 127(10), pp.1173-1182.

[15] Kosteski, N. and Packer, J.A., "Experimental examination of branch plate-to-RHS member connections", Proceedings of the $9^{\text {th }}$ International Symposium on Tubular Structures, Düsseldorf, Germany, Tubular Structures IX, A.A.Balkema Publishers, Lisse, The Netherlands, 2001, pp. 135-144.

[16] Karcher, D. and Puthli, R.S., "The static design of stiffened and unstiffened CHS L joints", Proceedings of the $9^{\text {th }}$ International Symposium on Tubular Structures, Düsseldorf, Germany, Tubular Structures IX, A.A.Balkema Publishers, Lisse, The Netherlands, 2001, pp. 221-228.

[17] Davies, G., Owen, J.S. and Kelly, R.B., "The effect of purlin loads on the capacity of overlapped bird beak K joints", Proceedings of the $9^{\text {th }}$ International Symposium on Tubular Structures, Düsseldorf, Germany, Tubular Structures IX, A.A.Balkema Publishers, Lisse, The Netherlands, 2001, pp.229-238.

[18] Willibald, S., Packer, J.A. and Puthli, R.S., "Experimental evaluation of bolted RHS flangeplate connection design models", Proceedings of the $9^{\text {th }}$ International Symposium on Tubular Structures, Düsseldorf, Germany, Tubular Structures IX, A.A.Balkema Publishers, Lisse, The Netherlands, 2001, pp.127-134.

[19] Jaurrieta, M.A., Alonso, A. and Chica, J.A., Eds., Proceedings of the $10^{\text {th }}$ International Symposium on Tubular Structures, Madrid, Spain, Tubular Structures X, A.A.Balkema Publishers, Lisse, The Netherlands, 2003.

[20] API, "Recommended practice for planning, designing and constructing offshore platforms RP-2A", American Petroleum Institute, USA, 1997.

[21] ISO TC67/SC7/WG3/P3, "Draft code provisions for section E", Revision R6, International Organization for Standardization, 1997.

[22] Dexter, E.M. and Lee, M.M.K., "Ultimate capacity of axially loaded K-joints in CHS", Proceedings of the $8^{\text {th }}$ International Symposium on Tubular Structures, Singapore, Tubular Structures VIII, A.A.Balkema Publishers, Lisse, The Netherlands, 1998, pp.259-268.

[23] Dier, A.F. and Lalani, M., "New code formulations for tubular joint static strength", Proceedings of the $8^{\text {th }}$ International Symposium on Tubular Structures, Singapore, Tubular Structures VIII, A.A.Balkema Publishers, Lisse, The Netherlands, 1998, pp.107-116.

[24] Yamada, Y., Morita, M., Makino, Y. and Wilmshurst, S.R., "A new ultimate capacity formula for unstiffened CHS T, TT, X, K and KK-joints under axial brace loads", Proceedings of the $8^{\text {th }}$ International Symposium on Tubular Structures, Singapore, Tubular Structures XIII, A.A.Balkema Publishers, Lisse, The Netherlands, 1998, pp.213-222. 
[25] Choo, Y.S. and Qian, X.D., "Recent research on tubular joints with very thick-walled chords", Proceedings of the $15^{\text {th }}$ International Offshore and Polar Engineering Conference, Seoul, Korea, 2005, Vol. IV, pp.272-278.

[26] Van der Vegte, G.J., Makino, Y. and Wardenier, J., "The effect of chord pre-load on the static strength of uniplanar tubular K-joints", Proceedings of the $12^{\text {th }}$ International Offshore and Polar Engineering Conference, Kitakyushu, Japan, 2002, Vol. IV, pp.1-10.

[27] Van der Vegte, G.J., Liu, D.K., Makino, Y. and Wardenier, J., "New chord load functions for circular hollow section joints", Cidect report 5BK-4/03, Stevin report 6.03.1 (revised), Cidect, UK, 2003.

[28] Pecknold, D.A., Ha, C.C. and Mohr, W.C., "Ultimate strength of DT tubular joints with chord preloads", Proceedings of the $19^{\text {th }}$ International Conference on Offshore Mechanics and Arctic Engineering, New Orleans, USA, 2000.

[29] Pecknold, D.A., Park, J.B. and Koppenhoefer, K.C., "Ultimate strength of gap K tubular joints with chord preloads", Proceedings of the $20^{\text {th }}$ International Conference on Offshore Mechanics and Arctic Engineering, Rio de Janeiro, Brazil, 2001.

[30] Van der Vegte, G.J., and Makino, Y., "Ultimate strength formulation for axially loaded CHS uniplanar T-joints", Proceedings of the $15^{\text {th }}$ International Offshore and Polar Engineering Conference, Seoul, Korea, 2005, Vol. IV, pp.279-286.

[31] Yura, J.A., "Ultimate capacity equations for tubular joints", OTC 3690, Houston, USA, 1980.

[32] Wardenier, J., Kurobane, Y., Packer, J.A., Dutta, D. and Yeomans, N., "Design guide for circular hollow section (CHS) joints under predominantly static loading", TUV-Verlag GmbH, Cologne, Germany, 1991.

[33] Choo, Y.S., "Recent development and innovation in tubular structures", Advances in Structural Engineering, 2005, 8(3), pp.217-230.

[34] Choo, Y.S., Liang, J.X. and Van der Vegte, G.J., "An effective external reinforcement scheme for circular hollow section joints", Connections in Steel Structures V - Amsterdam, 2004, pp.423-432.

[35] Choo, Y.S., Liang, J.X., Van der Vegte, G.J., and Liew, J.Y.R., "Static strength of doubler plate reinforced CHS X-joints loaded by in-plane moment", Journal of Constructional Steel Research, 2004, 60, pp.1725-1744.

[36] Choo, Y.S., Liang, J.X., Van der Vegte, G.J., and Liew, J.Y.R., "Static strength of collar plate reinforced CHS X-joints loaded by in-plane moment", Journal of Constructional Steel Research, 2004, 60, pp.1745-1760.

[37] Van der Vegte, G.J., Choo, Y.S., Liang, J.X., Zettlemoyer, N. and Liew, J.Y.R., "Static strength of T-joints reinforced with doubler or collar plates. Part II: Numerical simulations", Journal of Structural Engineering, ASCE, 2005, 131(1), pp.129-138.

[38] Lee, M.M.K. and Llewelyn-Parry, A., "Strength estimation of offshore ring-stiffened DT joints", Proceedings of the $10^{\text {th }}$ International Symposium on Tubular Structures, Madrid, Spain, Tubular Structures X, A.A.Balkema Publishers, Lisse, The Netherlands, 2003, pp.245-252.

[39] Willibald, S., "The static design of ring-stiffened tubular T- and Y-joints", Proceedings of the $9^{\text {th }}$ International Symposium on Tubular Structures, Düsseldorf, Germany, Tubular Structures IX, A.A.Balkema Publishers, Lisse, The Netherlands, 2001, pp.581-588.

[40] Pietrapertosa, C. and Jaspart, J-P., "Study of the behaviour of welded joints composed of elliptical hollow sections", Proceedings of the $10^{\text {th }}$ International Symposium on Tubular Structures, Madrid, Spain, Tubular Structures X, A.A.Balkema Publishers, Lisse, The Netherlands, 2003, pp.601-608.

[41] Choo, Y.S., Liang, J.X. and Lim, L.V., "Static strength of elliptical hollow section X-joint under brace compression", Proceedings of the $10^{\text {th }}$ International Symposium on Tubular 
Structures, Madrid, Spain, Tubular Structures X, A.A.Balkema Publishers, Lisse, The Netherlands, 2003, pp.253-258.

[42] Kurobane, Y., "New developments and practices in tubular joint design", IIW Doc. XV488-81 and XIII-1004-81, International Institute of Welding, Paris, France, 1981.

[43] Noordhoek, C. and Verheul, A., "Static strength of high strength steel tubular joints", ECSC Agreement 7210-MC/602-(F5.05d/93), 1996.

[44] Liu, D.K. and Wardenier, J., "Effect of the yield strength on the static strength of uniplanar K-joints in RHS”, Doc. IIW-XVE-04-293, Delft University, Delft, The Netherlands, 2005.

[45] Lu, L.H., de Winkel, G.D., Yu, Y. and Wardenier, J., "Ultimate deformation limit for tubular joints", Proceedings of the $6^{\text {th }}$ International Symposium on Tubular Structures, Melbourne, Australia, Tubular Structures VI, A.A.Balkema Publishers, Lisse, The Netherlands, 1994, pp.341-348.

[46] Mang, F., "Untersuchungen an Verbindungen von geschlossenen und offenen Profilen aus hochfesten Stählen“, AIF - Nr. 3347, Universität Karlsruhe, Germany, 1978.

[47] Packer, J.A. and Henderson, J.E., "Hollow structural section connections and trusses - A design guide", Canadian Institute of Steel Construction, Toronto, Canada, 1997. (also available in Chinese)

[48] Puthli, R.S., Herion, S., Boellinghaus, Th. and Florian, W., "Welding in cold-formed areas of rectangular hollow sections", Cidect final report and addendum 1A-6/05, Cidect, UK, 2005.

[49] EN 10219-Part 2, "Cold formed structural hollow sections of non-alloy and fine grain structural steels - Part 2: Tolerances, dimensions and sectional properties", CEN, Brussels, Belgium, 1998.

[50] NEN 6774, "Eisen aan de staalkwaliteit voor constructiestaalsoorten in relatie tot het brosse breukgedrag voor overwegend statisch belaste constructies", NEN, Delft, The Netherlands, 2000.

[51] Björk, T., Marquis, G., Kemppainen, R. and Ilvonen, R., "The capacity of cold-formed rectangular hollow section K-gap joints", Proceedings of the $10^{\text {th }}$ International Symposium on Tubular Structures, Madrid, Spain, Tubular Structures, X, A.A.Balkema Publishers, Lisse, The Netherlands, 2003, pp.227-234.

[52] Zhao, X-L., Herion, S., Packer, J.A., Puthli, R.S., Sedlacek, G., Wardenier, J., Weynand, K., Van Wingerde, A.M., and Yeomans, N.F., "Design guide for circular and rectangular hollow section welded joints under fatigue loading", Cidect design guide Nr. 8, TUVVerlag GmbH, Cologne, Germany, 2000.

[53] Keizer, R., Romeijn, A., Wardenier, J. and Glijnis, P.C., "The fatigue behaviour of diamond bird beak T-joints", Proceedings of the $10^{\text {th }}$ International Symposium on Tubular Structures, Madrid, Spain, Tubular Structures X, A.A.Balkema Publishers, Lisse, The Netherlands, 2003, pp. 303-310.

[54] Lie, S.T., Chiew, S.P., Lee, C.K. and Huang, Z.W., "Modelling through-thickness and surface cracks in tubular joints", Proceedings of the $9^{\text {th }}$ International Symposium on Tubular Structures, Düsseldorf, Germany, Tubular Structures IX, A.A.Balkema Publishers, Lisse, The Netherlands, 2001, pp.285-290.

[55] Qian, X., Dodds, R.H. and Choo, Y.S., "Elastic-plastic crack driving force for tubular Xjoints with mismatched welds", Engineering Structures, 2005, Vol. 27, Issue 9, pp.14191434.

[56] Oomens, M., Romeijn, A., Wardenier, J. and Dijkstra, O.D., "Development and validation of a 3D fracture mechanics model for thick-walled CHS T-joints", Proceedings of the $15^{\text {th }}$ International Offshore and Polar Engineering Conference, Seoul, Korea, 2005, Vol. IV, pp.333-340. 
[57] Doerk, O., Fricke, W. and Weissenborn, C., "Comparison of different calculation methods for structural stresses at welded joints", International Journal of Fatigue, 2003, 25(5), pp.359-369.

[58] Marshall, P.W. and Wardenier, J., "Tubular vs non-tubular hot spot methods", Proceedings of the $15^{\text {th }}$ International Offshore and Polar Engineering Conference, Seoul, Korea, 2005 Vol. IV, pp.254-263.

[59] Packer, J.A., "Whither tubular structures research?", Proceedings of the $10^{\text {th }}$ International Symposium on Tubular Structures, Madrid, Spain, Tubular Structures X, A.A.Balkema Publishers, Lisse, The Netherlands, 2003, pp.3-11.

[60] Wardenier, J., "From a tubular morning mist to the tubular morning glow", Proceedings of the $9^{\text {th }}$ International Symposium on Tubular Structures, Düsseldorf, Germany, Tubular Structures IX, A.A.Balkema Publishers, Lisse, The Netherlands, 2001, pp.3-12.

[61] Wardenier, J., "Hollow sections in structural applications", Bouwen met Staal, Rotterdam, The Netherlands, 2002. (also available in Chinese and Spanish) 